$\underline{\mathbf{P}-78}$

\title{
Standardization OF Piper Sarmentosum Roxb. Leaf Material and Extracts
}

\author{
Mohd Shahrul Ridzuan Hamil', Beh Hooi Kheng, Abdalrahim F.A. Aisha and Zhari Ismail \\ School of Pharmaceutical Sciences, Universiti Sains Malaysia, $11800 \quad$ Pulau Pinang, Malaysia; \\ E-mail: shahrul.ridzuan18@gmail.com
}

Piper sarmentosum Roxb. (Piperaceae) or Kadok, a herbaceous shrub is well known in South East Asian countries due to its medicinal properties. However, there is still a lack of data on the qualitative and quantitative parameters of $P$. sarmentosum. The purpose of this study is to standardize the leaf materials and its extracts to ascertain the quality, safety and efficacy. Standardization of the plant material was performed by using physico-chemical tests, UV and FTIR spectroscopy, HPTLC and HPLC analysis. The moisture content and total ash content was $7.40 \%$ and $10.81 \%$. Cold extractive values of ethanolic extract and water extract were $10.90 \%$, and $23.77 \%$, respectively. Hot extractive values of the above mentioned extracts were $17.30 \%$ and $29.99 \%$, respectively. IR spectra of leaf powder indicated bands at $3350 \mathrm{~cm}^{-1}(-\mathrm{OH}), 2918-2850 \mathrm{~cm}^{-1}(\mathrm{C}-\mathrm{H}), 1615-1500$ $\mathrm{cm}^{-1}$ (aromatic domain band) and 1200-1100 $\mathrm{cm}^{-1}$ (alkenes). UV profile of aqueous and ethanol extracts exhibited maximum absorption at $270 \mathrm{~nm}$. The absorption from $350-250 \mathrm{~nm}$ is characteristic to aromatic amides and phenolic compounds. Thin layer chromatography and high performance liquid chromatography analysis were performed using piperine as external standard. The results of this study can serve as reference data for P. sarmentosum leaves.

Keywords: Standardization, Piper sarmentosum, Piperaceae, piperine. 